\title{
Exceptional diazoxide sensitivity in hyperinsulinaemic hypoglycaemia due to a novel HNF4A mutation
}

\author{
Ved Bhushan Arya'1, Jennifer Kalitsi'1, Ann Hickey², Sarah E Flanagan ${ }^{3}$ and \\ Ritika R Kapoor
}

'Department of Paediatric Endocrinology, Variety Club Children's Hospital, King's College Hospital NHS Foundation Trust, London, UK, 2Department of Neonatology, King's College Hospital NHS Foundation Trust, London, UK, and IInstitute of Biomedical and Clinical Science, University of Exeter, Exeter, UK
Correspondence should be addressed to R R Kapoor

Email

ritikakapoor@nhs.net

\section{Summary}

Diazoxide is the first-line treatment for patients with hyperinsulinaemic hypoglycaemia $(\mathrm{HH})$. Approximately 50\% of patients with $\mathrm{HH}$ are diazoxide resistant. However, marked diazoxide sensitivity resulting in severe hyperglycaemia is extremely uncommon and not reported previously in the context of HH due to HNF4A mutation. We report a novel observation of exceptional diazoxide sensitivity in a patient with $\mathrm{HH}$ due to HNF4A mutation. A female infant presented with severe persistent neonatal hypoglycaemia and was diagnosed with $\mathrm{HH}$. Standard doses of diazoxide $(5 \mathrm{mg} / \mathrm{kg} / \mathrm{day})$ resulted in marked hyperglycaemia (maximum blood glucose $21.6 \mathrm{mmol} / \mathrm{L}$ ) necessitating discontinuation of diazoxide. Lower dose of diazoxide $(1.5 \mathrm{mg} / \mathrm{kg} /$ day) successfully controlled $\mathrm{HH}$ in the proband, which was subsequently confirmed to be due to a novel HNF4A mutation. At 3 years of age, the patient maintains age appropriate fasting tolerance on low dose diazoxide $(1.8 \mathrm{mg} / \mathrm{kg} /$ day $)$ and has normal development. Diagnosis in proband's mother and maternal aunt, both of whom carried HNF4A mutation and had been diagnosed with presumed type 1 and type 2 diabetes mellitus, respectively, was revised to maturity-onset diabetes of young (MODY). Proband's 5-year-old maternal cousin, also carrier of HNF4A mutation, had transient neonatal hypoglycaemia. To conclude, patients with HH due to HNF4A mutation may require lower diazoxide than other group of patients with $\mathrm{HH}$. Educating the families about the risk of marked hyperglycaemia with diazoxide is essential. The clinical phenotype of HNF4A mutation can be extremely variable.

\section{Learning points:}

- Awareness of risk of severe hyperglycaemia with diazoxide is important and patients/families should be accordingly educated.

- Some patients with HH due to HNF4A mutations may require lower than standard doses of diazoxide.

- The clinical phenotype of HNF4A mutation can be extremely variable.

\section{Background}

Hyperinsulinaemic hypoglycaemia $(\mathrm{HH})$ is the most frequent cause of severe and persistent hypoglycaemia in infants and children (1). It is characterised by inappropriate secretion of insulin in the presence of low blood glucose (BG) concentrations. Mutations in a number of key genes (including ABCC8, KCNJ11, GLUD1, GCK, HADH, SLC16A1, HNF4A and HNF1A) involved in the regulation of insulin secretion from pancreatic $\beta$-cells have been described as the underlying molecular mechanisms leading to congenital $\mathrm{HH}$ (2). The phenotype of dominant 
mutations in $H N F 4 A$ is characterised by neonatal $\mathrm{HH}$ which evolves to diabetes mellitus in later life $(3,4)$. The first-line treatment in $\mathrm{HH}$ is diazoxide therapy, which at the doses of $5-20 \mathrm{mg} / \mathrm{kg} /$ day is effective in patients with heterozygous HNF4A mutations. We describe a novel finding of exceptional diazoxide sensitivity in an infant with HH due to a novel heterozygous HNF4A mutation.

\section{Case presentation}

The female proband was born at $37+1$ weeks (birth weight $3610 \mathrm{~g}(+1.6$ SDS) $)$ by emergency Caesarean section (foetal decelerations) to non-consanguineous Caucasian parents. Apgar scores at 1 and 5 min were 9 and 10 respectively. The proband's mother had presumed type 1 diabetes mellitus since age 17 years, well controlled on continuous subcutaneous insulin infusion. The proband developed severe persistent hypoglycaemia soon after birth, requiring high glucose infusion $(17.5 \mathrm{mg} / \mathrm{kg} / \mathrm{min})$. Apart from macrosomia, physical examination was unremarkable.

\section{Investigations}

A hypoglycaemia screen confirmed the diagnosis of $\mathrm{HH}$ (BG $2.6 \mathrm{mmol} / \mathrm{L}$, serum insulin $40.3 \mathrm{mIU} / \mathrm{L}$, nonesterified fatty acids $0.10 \mathrm{mmol} / \mathrm{L}, \quad \beta$-hydroxybutyrate $<0.10 \mathrm{mmol} / \mathrm{L}$ ). All other investigations including acylcarnitine profile, serum cortisol, serum lactate, serum ammonia and plasma amino acids were normal.

\section{Treatment}

The proband was commenced on standard doses of diazoxide $(5 \mathrm{mg} / \mathrm{kg} /$ day in three divided doses) and chlorothiazide $(7.5 \mathrm{mg} / \mathrm{kg} / \mathrm{day}$ in two divided doses) on day 15 of life.

\section{Outcome and follow-up}

Within $48 \mathrm{~h}$ of commencing diazoxide, marked hyperglycaemia (highest bedside BG concentration $21.6 \mathrm{mmol} / \mathrm{L}$ ) developed, which persisted despite weaning high-concentration glucose intravenous infusion to full enteral feeds (Fig. 1). Diazoxide was withheld and eventually stopped after 4 days. Following discontinuation, BG concentration gradually decreased followed by recurrence of hypoglycaemia. A repeat hypoglycaemia screen confirmed persistence of HH (BG $2.6 \mathrm{mmol} / \mathrm{L}$ and serum insulin $48.4 \mathrm{mIU} / \mathrm{L})$. Additionally, high glucose

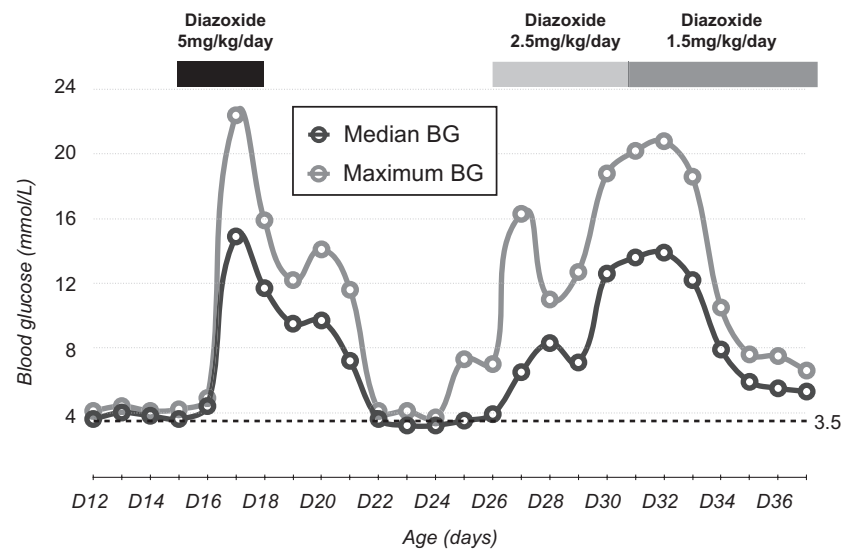

Figure 1

Blood glucose response to diazoxide in an infant with hyperinsulinaemic hypoglycaemia due to a novel HNF4A mutation. BG, blood glucose; D, day of life.

infusion rate $(13.5 \mathrm{mg} / \mathrm{kg} / \mathrm{min})$ was required to maintain BG concentration greater than $3.5 \mathrm{mmol} / \mathrm{L}$. Administration of glucagon $(200 \mathrm{mcg} / \mathrm{kg})$ raised the $B G$ concentration from $2.3 \mathrm{mmol} / \mathrm{L}$ to $7.3 \mathrm{mmol} / \mathrm{L}$, also in keeping with $\mathrm{HH}$. Lower dose diazoxide $(2.5 \mathrm{mg} / \mathrm{kg} /$ day $)$ was started, after which glucagon infusion and intravenous fluids were quickly weaned. Despite lower doses, hyperglycaemia developed, necessitating further reduction in diazoxide $(1.5 \mathrm{mg} / \mathrm{kg} /$ day $)$. On this minimal diazoxide dose, BG concentration on demand feeds ranged between 3.9 and $7.5 \mathrm{mmol} / \mathrm{L}$ and were maintained after a 6 -h fast. As body weight increased with age, the patient needed corresponding increase in diazoxide dose to maintain euglycaemia. At age 2.75 years, the patient required further increase in the dose of diazoxide due to occasional hypoglycaemic episodes implying persistence of $\mathrm{HH}$. At last follow-up (age 3.1 years), the patient has normal development and remains on low-dose diazoxide $(1.8 \mathrm{mg} / \mathrm{kg} /$ day) with stable BG profile and age-appropriate fasting tolerance.

Molecular genetic testing identified a maternally inherited heterozygous nonsense mutation (p. Ser419Ter; c.1256C>G) in HNF4A (NM_175914.4). The proband mother's diagnosis was revised from type 1 diabetes mellitus to maturity-onset diabetes of young (MODY). Family history revealed young-onset diabetes mellitus in maternal aunt and maternal grandfather who had been labelled type 2 diabetes mellitus and treated with metformin. Genetic analysis confirmed that maternal aunt was heterozygous for the same mutation, leading to change in her diagnoses and treatment (now on sulphonylurea therapy). Maternal grandfather unfortunately had died of complications secondary to diabetes mellitus at 76 years 
before he could be tested for HNF4A mutation. A 5-yearold maternal cousin tested positive for same mutation. His birth weight was $3844 \mathrm{~g}(+1.4$ SDS). He had transient neonatal hypoglycaemia that did not necessitate any intervention. He is currently asymptomatic, with normal HbA1C and glucose tolerance.

\section{Discussion}

Diazoxide is the first-line drug used in the management of $\mathrm{HH}$, standard doses being $5-20 \mathrm{mg} / \mathrm{kg}$ per day in three divided doses (5). HH patients secondary to HNF4A mutations are diazoxide responsive $(3,6)$. Improda et al. described a case of HNF4A mutation who was managed on a lower dose of diazoxide ( $2 \mathrm{mg} / \mathrm{kg}$ per day) (7). However, the described patient had a fasting tolerance of $3.5 \mathrm{~h}$ and the authors did not specify reasons for using lower doses. Our patient is the first reported case of HNF4A mutation that required careful titration of diazoxide to a minimal dose of $1.5 \mathrm{mg} / \mathrm{kg} /$ day to avoid hyperglycaemia.

There are case reports in the literature of hyperglycaemic hyperosmolar coma with diazoxide $(8,9)$. Balsam et al. reported a 13-month-old infant who developed hyperosmolar hyperglycaemic coma on diazoxide (8). The patient presented with listlessness associated with severe hyperglycaemia (BG: $111 \mathrm{mmol} / \mathrm{L}$ ) approximately 10 days after discharge from hospital on diazoxide $7.5 \mathrm{mg} / \mathrm{kg}$ per day and hydrochlorothiazide $12.5 \mathrm{mg}$ per day. After initial management with intravenous insulin and intravenous fluids, hypoglycaemia recurred requiring reinstitution of diazoxide at lower dose $(4 \mathrm{mg} / \mathrm{kg}$ per day). The authors reported that the BG concentration had been well controlled for 4 months on the lower doses of diazoxide. Mangla et al. recently reported a 16 month-old-child who developed severe hyperglycaemia (BG $>22 \mathrm{mmol} / \mathrm{L}$ ) and ketosis during intercurrent illness while receiving diazoxide $(15 \mathrm{mg} / \mathrm{kg}$ per day) for $\mathrm{HH}$ diagnosed at 4 months of age (9). Cessation of diazoxide treatment and institution of insulin treatment was temporarily required. However, hypoglycaemia recurred within few days and the patient needed diazoxide $20 \mathrm{mg} / \mathrm{kg}$ per day, which he was on at 28 months of age, to maintain stable BG concentration. Mutation status of these patients was not known. Arguably, had our patient not had close BG monitoring, she would have been at a substantial risk of developing hyperglycaemic hyperosmolar coma. This case highlights the importance of awareness of risk of severe hyperglycaemia with diazoxide and to educate the family to observe for persistently high along with low $B G$ readings.

The mechanism underling $\mathrm{HH}$ in early life and switch to MODY in HNF4A mutation carriers is not understood. Perhaps the same mechanisms underlie the predisposition to developing higher BG levels on diazoxide. To the best of our knowledge, marked hyperglycaemia on standard doses of diazoxide in a patient with $H N F 4 A$ mutation has previously not been described. As this is a novel HNF4A mutation, it is plausible that this predisposition is mutation specific.

This case study also highlights the clinical heterogeneity well known to be associated with $H N F 4 A$ mutation carriers, demonstrating the entire spectrum in the same family with asymptomatic neonatal periods to transient $\mathrm{HH}$ in proband's cousin and persistent $\mathrm{HH}$ in proband (4). The phenotype of DM is also varied with young-onset (17 and 22 years in proband's mother and proband's maternal aunt respectively) but subcutaneous insulin requirement in proband's mother to successful management with oral hypoglycaemic agents in maternal aunt and maternal grandfather. Maternal grandfather (likely carrier of HNF4A mutation) had later presentation of diabetes (30 years) with aggressive progression and complications leading to death at 76 years.

To conclude, awareness of risk of marked hyperglycaemia/hyperglycaemic hyperosmolar coma with diazoxide therapy is essential. Patients with $\mathrm{HH}$ due to HNF4A patients may require lower diazoxide than other group of patients with $\mathrm{HH}$.

\section{Declaration of interest}

The authors declare that there is no conflict of interest that could be perceived as prejudicing the impartiality of the research reported.

\section{Funding}

This research did not receive any specific grant from any funding agency in the public, commercial or not-for-profit sector.

\section{Patient consent}

Written informed consent has been obtained from the patient's guardian for publication of the submitted article and accompanying images.

\section{Author contribution statement}

$\checkmark \mathrm{B}$ A researched data and wrote the manuscript. J K, S E F, A H and R K K reviewed the manuscript and contributed to discussion. $\mathrm{RKK}$ conceptualised the idea of the manuscript and is the named physician for the patient. The authors are grateful to the Department of Molecular Genetics at the Royal Devon and Exeter Hospital for performing the genetic studies. 


\section{References}

1 Aynsley-Green A, Hussain K, Hall J, Saudubray JM, Nihoul-Fekete C, De Lonlay-Debeney P, Brunelle F, Otonkoski T, Thornton P \& Lindley KJ. Practical management of hyperinsulinism in infancy. Archives of Disease in Childhood: Fetal and Neonatal Edition 200082 F98-F107. (https://doi.org/10.1136/fn.82.2.F98)

2 Arya VB, Mohammed Z, Blankenstein O, De Lonlay P \& Hussain K. Hyperinsulinaemic hypoglycaemia. Hormone and Metabolic Research 201446 157-170. (https://doi.org/10.1055/s-00341367063)

3 Kapoor RR, Locke J, Colclough K, Wales J, Conn JJ, Hattersley AT, Ellard S \& Hussain K. Persistent hyperinsulinemic hypoglycemia and maturity-onset diabetes of the young due to heterozygous HNF4. A mutations. Diabetes 200857 1659-1663. (https://doi.org/10.2337/ db07-1657)

4 Pearson ER, Boj SF, Steele AM, Barrett T, Stals K, Shield JP, Ellard S, Ferrer J \& Hattersley AT. Macrosomia and hyperinsulinaemic hypoglycaemia in patients with heterozygous mutations in the HNF4A gene. PLoS Medicine 20074 e118. (https://doi.org/10.1371/ journal.pmed.0040118)
5 Kapoor RR, Flanagan SE, James C, Shield J, Ellard S \& Hussain K. Hyperinsulinaemic hypoglycaemia. Archives of Disease in Childhood 200994 450-457. (https://doi.org/10.1136/adc.2008.148171)

6 Flanagan SE, Kapoor RR, Mali G, Cody D, Murphy N, Schwahn B, Siahanidou T, Banerjee I, Akcay T, Rubio-Cabezas O, et al. Diazoxideresponsive hyperinsulinemic hypoglycemia caused by HNF4A gene mutations. European Journal of Endocrinology 2010162 987-992. (https://doi.org/10.1530/EJE-09-0861)

7 Improda N, Shah P, Guemes M, Gilbert C, Morgan K, Sebire N, Bockenhauer D \& Hussain K. Hepatocyte nuclear factor-4 Alfa mutation associated with hyperinsulinaemic hypoglycaemia and atypical renal Fanconi syndrome: expanding the clinical phenotype. Hormone Research in Paediatrics 201686 337-341. (https://doi. org/10.1159/000446396)

8 Balsam MJ, Baker L \& Kaye R. Hyperosmolar nonketotic coma associated with diazoxide therapy for hypoglycemia. Journal of Pediatrics 197178 523-525. (https://doi.org/10.1016/S0022-3476(71)80241-X)

9 Mangla P, Hussain K, Ellard S, Flanagan SE \& Bhatia V. Diazoxide toxicity in a child with persistent hyperinsulinemic hypoglycemia of infancy: mixed hyperglycemic hyperosmolar coma and ketoacidosis. Journal of Pediatric Endocrinology and Metabolism 201831 943-945. (https://doi.org/10.1515/jpem-2018-0112)

Received in final form 5 April 2019

Accepted 25 April 2019 